\title{
A REVIEW OF TPACK AND SAMR MODELS: HOW SHOULD LANGUAGE TEACHERS ADOPT TECHNOLOGY?
}

\author{
Justsinta Sindi Alivi \\ (s.alivi@warwick.ac.uk)
}

University of Warwick, The United Kingdom

$\begin{array}{ll}\text { ARTICLE } & \text { ABSTRACT } \\ \text { Keywords: } & \text { This paper primarily aims at reviewing the idea of Technological Pedagogical } \\ \text { and Content Knowledge (TPACK) as well as the application of Substitution, } \\ \text { Augmentation, Modification, and Redefinition (SAMR) frameworks in } \\ \text { teaching practices. In particular, this paper is expected to provide insight for } \\ \text { language teachers interested in Information and Communication Technology } \\ \text { Language teaching and } \\ \text { (ICT) incorporation to teaching as regards TPACK and SAMR understanding. } \\ \text { Accordingly, the language teachers are expected to be able to incorporate } \\ \text { technology into teaching appropriate ways reflecting the frameworks. Further, } \\ \text { a description of how TPACK and SAMR carried out in teaching is presented to } \\ \text { provide teachers with a clear definition of the frameworks. Additionally, some } \\ \text { views concerning the challenges of the application are also discussed as an } \\ \text { evaluation.. }\end{array}$

\section{INTRODUCTION}

The rapid development of technology comes along with the increase in technology active users worldwide. Hootsuite and we are Social, digital content management platforms, reported that $50 \%$ of the global population as active internet users and approximately $67 \%$ use mobile devices in 2019, and the trend is indicated growing annually (Kemp, 2019). The fame of technology use urges pedagogical stakeholders to adjust and update their educational policy to public demand. Teachers, who are mostly ICT users, are advocated to shift their teaching attitudes to embark integrating technologies into teaching practices. Additionally, the change of the technology trend is argued by Reid (2014) as a tenet leading students' demand to force teachers to integrate ICT into teaching and learning tasks. 
Before the popularity of technology, teachers used various manual tools as teaching media to assist students' learning. They used blackboards and chalks to explain materials, presented real objects to the classroom for providing the students with real examples, used papers for students' worksheets. Technology has gradually taken over these manual tools as teaching media into digital devices. The invention of radios and televisions encouraged teachers to utilize it into classroom activities, for instance, podcasting, showing news. Further, the role of technologies previously used as material delivery has developed into interactive media (Selwin, 2017). The emergence of the internet and emails have led the teachers to utilize it as communication. The communication provides students with affordance to learn outside classrooms asynchronously. The students can consult the teachers via email for any emerging question without seeing the teacher in person. The students can email the assignment without having printout submission. In current development, a lot of mobile and online media are invented, e.g., Learning Management Systems (LMS), social media, instant messaging, websites, web search engines. These offer the users (i.e., both teachers and students) with affordance to have synchronous communication, allowing them having live interaction online. This interactive online has initiated most teachers to use it for students' online collaboration, online feedback, as well as online assignments (e.g., creating videos and upload them to social media).

In language teaching, ICT is deliberated, having more roles than other content subjects. Language learning requires learners to have more practices to achieve better improvement in their language performance. ICT provides the learners with affordance and access to meet authentic materials supporting their learning through both guided and self-directed processes. Authentic materials are promoted to use in language teaching and learning as it offers learners to have samples about the real-context application of how the language is used in the native language community (Shadiev et al., 2018; Al Azri and Al-Rashdi, 2014). Authentic materials can be found in the forms of news, books, articles, videos written and created by native language users. Previously, the authentic materials were presented in the printed form. Nowadays, we can find ample digital authentic materials on the internet. Materials about language learning are abundantly and easily found in social media (e.g., Youtube, Instagram, Facebook) and educational websites or blogs (e.g., British Council Learn English, Duolingo, BBC Learn English). The learners can practice listening independently and ubiquitously using Youtube videos or Spotify Podcasts. They can train their reading skills by reading BBC news or English-written articles available on the internet or improve their writing ability through blogging or Facebook posts. The learners can also 
practice their speaking skills by creating videos in Youtube or video conferencing with any speaker worldwide.

Regarding the benefits of ICT in pedagogy, particularly language teaching and learning, language teachers are suggested and encouraged to enhance their ICT competence and integrate it into their pedagogical practice. However, the teachers' ICT competency is defined not merely having technical skills in technology operation, but more to acquire competence of TPACK and be able to apply it into various levels of SAMR. Further discussion about TPACK and SAMR is presented in the following sections.

\section{The Tpack Framework}

Teaching and learning are commonly defined as a process of transferring knowledge from teachers to learners purposing to achieve learning objectives. In order to attain the objective, teachers should acquire some skills and knowledge both in subject matters and pedagogy. This concept is firstly proposed by Shulman (1986), popular with Pedagogical Content Knowledge (PCK) Frameworks. In Pedagogical Knowledge (PK), teachers should have competences on how to teach students, as well as holding good comprehension of concepts and theories of teaching. For example, having skills in teaching strategies and methods, identifying students' needs and learning styles, making a fair and objective assessment, preparing lesson plans, applying proper and effective classroom management in the Content Knowledge (CK) requires teachers to have good understanding and mastery on relevant teaching materials according to the disciplines they teach. For instance, in English language teaching, teachers should be competent in language skills (i.e., listening, speaking, reading, writing) and language components (i.e., grammar, vocabulary) of English. They should also know about cultures and contexts of English application, including distinct accents and pronunciation in types of standard English (e.g.,, American English, British English, Australian English).

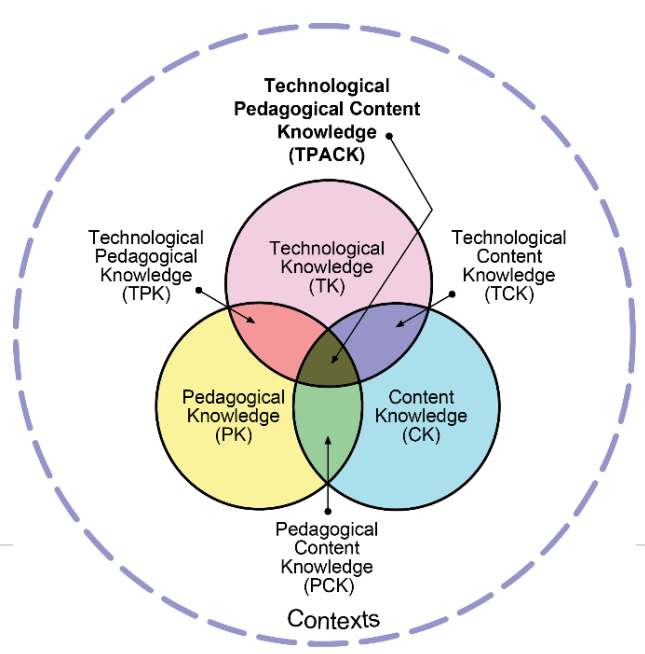


Fig. 1. The TPACK Framework and Its Knowledge Components (http://tpack.org)

The PCK framework is redesigned by Mishra and Koehler (2006) by adding a new competence, Technological Knowledge (TK), which is further popular as TPACK (Technological Pedagogical and Content Knowledge) Frameworks. In technological knowledge, teachers are advised to have functional ICT competences. However, technological competence is not defined as acquiring capabilities in ICT technical skills. Instead, teachers should be able to implement the interaction among the main three knowledge domains (TK, CK, and PK) in teaching practices which highlight the use of technologies in constructive ways. The ways can help learners deal with learning problems and develop knowledge (Koehler, Mishra, and Cain, 2013). Specifically, the function of technologies in TPACK is as learning tools to help teachers enhance teaching instructions (Niess, 2011), at the same time, assist students to be more engaged and interactive in their learning experience. In the context of EFL teaching, teachers should have good comprehension in EFL materials, and they can critically and innovatively teach the materials with varied activities and teaching techniques using appropriate technologies to support learners achieving a successful learning objective.

Literature suggests the emergence of teachers' Continuing Professional Development (CPD) in order to foster teachers' TPACK knowledge. Teachers' professional development in the forms of workshops, training, seminars are believed useful to accommodate teachers to update and upgrade their technical competence as well as knowing how to use and integrate it into teaching. Some studies have indicated the effectiveness of TPACK CPD to enhance the teachers' TPACK competence. Rienties et al. (2013) reported that nearly half of the research participants (73 teachers) showed positive changes in attitudes toward ICT use after twelve weeks of online TPACK training. Similarly, Oakley and Pegrum (2015) found that two higher education teachers (i.e., the research participants) in Australia developed their TPACK competence after joining TPACK CPD carried out by the institution. Nonetheless, the efficacy of TPACK training should meet the teachers' needs, how to teach subject content knowledge using ICT, which one subject may be different from other subjects. This training is pointed out by Mishra and Koehler (2006) that "there is no single technological solution that applies for every teacher, every course, or for every view of teaching." (p. 1029) 


\section{The SAMR Model}

The implementation of TPACK is widely related to the SAMR (Substitution, Augmentation, Modification, and Redefinition) model. This model is popularized by Puentedura (2006), illustrating a hierarchy of technological integration by teachers in pedagogical practice as an evaluation model of teachers' ICT adoption. It starts with Substitution as the lowest level to Redefinition as the highest one.

As the SAMR model indicates the evaluation of the integration between pedagogy and ICT in practices, this model is commonly associated with Bloom's Taxonomy application. Bloom's Taxonomy shows a classification of cognitive levels in learning. Benjamin Bloom introduced this classification in 1956, suggesting teachers to guide students achieving higher-order thinking skills or critical abilities in learning. Similarly, the SAMR Model encourages teachers to incorporate ICT into teaching by constructing and enhancing students' learning processes to attain more critical learning performance. Bloom's Taxonomy (Bloom et al., 1956) levels from the lowest to the highest initially include Knowledge, Comprehension, Application, Analysis, Synthesis, Evaluation. It is revisited by Anderson, et al. (2001) by eliminating Synthesis, exchanging it into Evaluate, and put Create at the top level. Accordingly, the revised Bloom's Taxonomy order (Anderson, et al, 2001) is Remember, Understand, Apply, Analyse, Evaluate, and Create, respectively. In the SAMR model, Substitution and Augmentation levels are in conjunction with Remember, Understand, and Apply levels (in Bloom's Taxonomy). The upper levels, Modification, and Redefinition are on the same level as Analyse, Evaluate, and Create. Both SAMR and Bloom's Taxonomy, achieving the highest level in each hierarchy, does not mean without a process. It embarks from the lowest level to be able to equip students with the basic knowledge they will use to critically implement in the highest level of learning activities (Hilton, 2016).

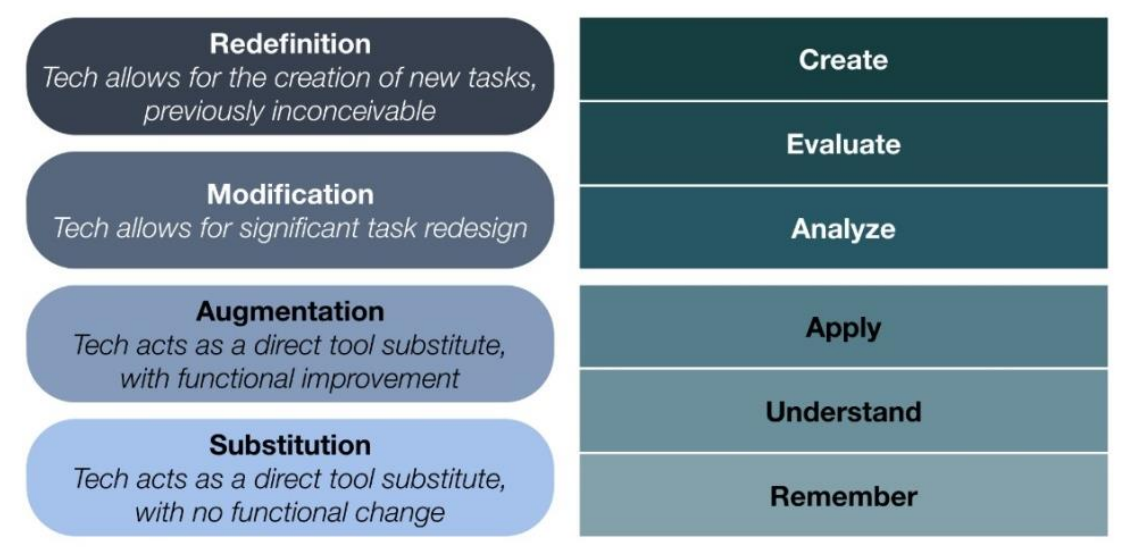


Fig. 2. SAMR and Bloom's Taxonomy: Assembling the Puzzle (Puentedura, 2014)

Following Puentedura's SAMR model (2006), Substitution means "tech acts as a direct tool substitute, with no functional change." In practice, the Substitution process refers to replacing manual teaching instruments to digital. For instance, teachers substitute the use of whiteboards or printout materials as material delivery tools to interactive whiteboards (i.e., using projectors), our students write for writing practices using personal laptops instead of writing on papers. Augmentation indicates "tech acts as a direct tool substitute, with functional improvement."

The Augmentation process is similar to the Substitution, yet it provides students with some functions of technological use. The example of teaching activities in the Augmentation level is the students practice their writing using Microsoft word. However, they use a thesaurus or apply google translate to find the words' synonym or antonym, using check documents (in the word processing tool) or Grammarly (a free writing assistance software) for spelling and grammatical checkers. In this writing process, students do not only use ICT (i.e., laptop, Ms. Words) for writing, but they also use other ICT functions (i.e., thesaurus, Grammarly), allowing them to learn more knowledge in the process.

If the previous levels focus on learning task enhancement, the following levels are more in learning task transformation, requiring the involvement of higher-order thinking skills. The third level is Modification referring to "tech allows for significant task redesign." In this level, the application of technologies does not merely involve more technological functions, but ICT offers students to have different kinds of learning tasks. For example, students are given a task to write collaboratively using Google Doc., and then they give peer feedback online in the Google Doc. platform. In this activity, Google Doc. does not only act as a digital platform to write, but it is modified as a collaborative platform in an online environment. The students can evaluate (i.e., give feedback) their writing to each other online. The other example, students make a poster presentation using Canva (a graphic design tool website) for writing activities. In the poster making the process, students are challenged their activity to write in a concise yet comprehensive manner, as well as making the poster as attractive as possible by providing relevant images to help readers easily comprehend information in the poster. In this process, the students learning task is not only writing some ideas, but it is modified by giving other learning tasks (e.g., summarizing, researching for related images). 
The highest integration level is Redefinition indicating "tech allows for the creation of new tasks, previously inconceivable." This level emphasis more creativity in students' learning tasks. The students are encouraged to be able to practice their language skills in various forms in real-life contexts, which might be challenging to implement without technologies. For instance, in speaking skills, students are instructed to make a video and upload it to Youtube so that they can reach worldwide viewers; or the teacher provides video conferences with native English speakers so that students can get tangible speaking practices. The other activity is using social media for writing skills, for example, is Facebook. Students are instructed to post their views in English on Facebook and let other students give responses or comments concerning the post. This type of social media allows students to have opportunities for broader access to communication with worldwide Facebook users.

The SAMR model brings light to teachers for developing their TPACK competence as, according to Kirkland (2014), "using technology effectively means creating the kind of rich tasks that redesign traditional ways of learning and create opportunities that do not exist without the use of technology." Besides, this model assists the teachers in assessing their TPACK competence levels and know how to use technology effectively in pedagogical activities. The application of SAMR is also claimed by Kirkland (2014) that SAMR tends to be more learner-centered as each level of SAMR application emphasizes. The SAMR proves that the students are active in each learning task using ICT, and the higher the level, the more engaged the students achieving their autonomous learning capacity.

\section{Opportunities and Challenges}

Many studies have examined how teachers use ICT in their teaching practices about the TPACK and SAMR framework. Many studies indicated that ICT could offer teachers with facilities for online communication, feedback, and learning collaboration. ICT can help teachers to make them more accessible, search abundant teaching materials on the internet, administer the online assessment, and allow them to guide students having autonomous learning. Besides, ICT use in pedagogy has been shown successfully to trigger students' learning motivation and hold longer attention (Hilton, 2016).

Patria (2019) reported research about the utilization of iPad in English teaching and learning in the Philippines through surveys to 966 English learners and 8 English teachers followed 
by classroom observations and interviews. It was shown that all teachers used iPad to integrate different pedagogical activities. The activities comprise writing texts, creating essays, writing notes, answering quizzes, researching sources from the internet, browsing the web, accessing materials in LMS, utilizing LMS features, checking grammar online, presenting a multimedia presentation, watching and recording video materials, and creating a digital portfolio." In accordance with these activities, it is shown that the teachers frequently implemented augmentation in pedagogical activities. Furthermore, the learners revealed that they were benefited from the iPad capacity providing them with practical, mobile, and accessible use to gather any relevant information or learning materials and allowing them to be more engaged in learning activities.

Nevertheless, among the opportunities given by technologies, many teachers are still not in favor of integrating ICT into teaching. Some factors such as instrumental pedagogic styles, lack of technological resources, low perceived use of technologies, limited experience in ICT professional development, and the absent of firm policy of ICT use are the reasons emerging teachers' reluctance in ICT incorporation. This effect on the application of the TPACK and SAMR framework in practice.

In Tanzania, Kihoza, et al. (2016) assessed and evaluated ICT use challenges and opportunities experienced by higher education teachers $(\mathrm{N}=206)$ from various disciplines. It was shown that lack of technological supports, teachers' reluctance to change, and lack of knowledge on technology use in education were the challenge to the framework's embodiment. This is further explained that the teachers' insufficient competence in educational technology impeded them to prepare and integrate ICT in teaching innovatively.

In the USA, Hilton (2016) examined two teachers from a school in Southern Pennsylvania to reflect TPACK and SAMR application in a case study. The findings noted that despite holding professional competence in TPACK, the teachers were challenged with the conservative district policy. It is reported that the district technology department was careful with schools' website security as an attempt to avoid unnecessary and inappropriate content. This content has made teachers to have long-wait and did a complicated procedure to get approval for unblocking specific websites and downloading required applications.

In Philippine, Patria (2019) research participants (both students and teachers) revealed that despite gaining advantages from technological (i.e., iPad) use in teaching and learning tasks, they 
also experienced some difficulties in terms of technical problems and personal challenges. These covered "limitation of iPad and its apps' functions, appropriateness of iPad use to language tasks." Also, the users were dependent on the internet, challenging to move on from pen and paper use, difficult to organizing materials files, less familiar with iPad utilization, distracted (i.e., not focus), and disregarded textbooks.

Furthermore, compared to traditional technologies (e.g., pencils, chalkboards), digital technologies (e.g., computers, software applications) are deliberated more challenging for teachers as they are protean, unstable, and opaque (Mishra and Koehler, 2013; Papert, 1980; Turkle, 1995). Protean means that modern technologies offer ample affordance to allow users to use it for various activities in any aspect of life (e.g., entertainment, economics, communication, education). Besides, technologies require the users to have skills for operating it (opaque). Moreover, the characteristics of digital technologies that are dynamic, rapidly changing, and developing (unstable) force the users to upgrade their technical skills and be innovative to integrate it into daily activities. This is also asserted by Kirkland (2014) "designing a rich learning task is a challenge for any teacher and trying to synthesize the dynamic world of technology into the mix adds an extra element of risk and uncertainty." Hence, as users, teachers are also confronted with the challenge of modern technology characteristics. Technologies used by students (i.e., younger generation) must be different from the teachers used in their generation. Consequently, the teachers should understand this social demand and keep alert and open to adjust and upgrade their teaching to the current and future era.

\section{CONCLUSION}

The application of TPACK and SAMR frameworks is intended to advise teachers in the use of ICT, offering more opportunities for learners to learn the application independently. Nonetheless, it does not mean that teaching is obligated to use technology for every activity. Technologies take roles as learning tools to assist and enhance language learning activities. The use of either non-technology or using technology instructions does not determine the efficacy of learning activities. Both can be successful and foster the teaching and learning process if they are carried out with students' needs. Despite this, the ICT contribution to language pedagogy is necessary to take into account as it provides more roles than the instrumental one (e.g., blackboard, pencil-and-paper) for its affordance of authentic material access and worldwide communication. 
Therefore, language teachers are suggested to integrate ICT (i.e., TPACK) by enhancing levels of tasks about the SAMR model. Some gradual processes are required by introducing students with some technologies, embarking on using it as a substitution device, improving to augmentation tasks. When the students are becoming more familiar with the ICT use, teachers can incorporate ICT into higher-level tasks by letting students be more creative and having more practice in language learning utilizing technology.

The challenge of the TPACK application is that technologies are still dependent on technical aspects and connections. Despite facilitated with excellent ICT facilities and resources, the teachers should be aware of the possibility of ICT use problems. Therefore, some teaching plans should be prepared to anticipate the limitation.

\section{REFERENCES}

Kemp, S. (2019). Digital trends 2019: Every single stat You need to know about the internet. https://thenextweb.com/contributors/2019/01/30/digital-trends-2019-everysingle-stat-you-need-to-know-about-the-internet/ (Accessed on September 17, 2019)

Puentedura, R. (2014). SAMR and Bloom's Taxonomy: Assembling the Puzzle.https://www.commonsense.org/education/articles/samr-and-bloomstaxonomy - assembling-the-puzzle (Accessed on September 28, 2019)

Hilton, J. T. (2016). 'A case study of the application of SAMR and TPACK for reflection on technology integration into two social studies classrooms,' The Social Studies, 107 (2), 68-73.

Kirkland, A. B. (2014). 'Models for technology integration in the learning commons,' School Libraries in Canada, 32 (1), 14-18.

Rienties, B., Brouwer, N. and Lygo-Baker, S. (2013) 'The effects of online professional development on higher education teachers' beliefs and intentions towards learning facilitation and technology,' Teaching and Teacher Education. Elsevier Ltd, 29(1), pp. $122-131$.

Oakley, G., and Pegrum, M. (2015). 'Engaging in Networked Learning: Innovating at the Intersection of Technology and Pedagogy', Education Research and Perspectives (Online), 42, pp. 397-428.

Reid, P. (2014). 'Categories for barriers to adoption of instructional technologies,' Education and Information Technologies, 19(2), pp. 383-407. 
Selwyn, N. (2017). Education and Technology: Key Issues and Debates Second Edition. London: Bloomsbury.

Shadiev, R. et al. (2018). 'International Forum of Educational Technology \& Society Guest Editorial: Authentic Edutainment with Advanced Technologies Published by International Forum of Educational Technology \& Society Linked references are available on JSTOR for this article : G,' 21(4), pp. 111-114.

Al Azri, R. H., and Al-Rashdi, M. H. (2014). 'The effect of using authentic materials in teaching', International Journal of Scientific and Technology Research, 3(10), pp. 249-254.

Mishra, P., and Koehler, M. J. (2006). 'Technological pedagogical content knowledge: A framework for teacher knowledge', Teachers College Record, Vol. 108, No. 6, p. 1017-1054.

Shulman, L. (1986). 'Those who understand: Knowledge growth in teaching. Educational Researcher, 15(2), p. 4-44.

Koehler, M. J., Mishra, P., and Cain, W. (2013). 'What is technological pedagogical content knowledge (TPACK)?', Journal of Education, 193 (3), p. 13-19.

Papert, S. (1980). Mindstorms: Children, Computers, and Powerful Ideas. New York: Basic Books.

Turkle, S. (1995). Life on the Screen: Identity in the Age of the Internet. New York: Simon \& Schuster.

Niess, M. L. (2011). 'Investigating TPACK: Knowledge growth in teaching with technology,' J. Educational Computing Research, 44 (3) p. 299-317.

Bloom, B. S. (1965). Taxonomy of Educational Objectives: The Classification of Educational Goals. New York: David McKay Company.

Anderson, L.W., and Krathwohl, D.R. (2001). A Taxonomy for Learning, Teaching, and Assessing: A Revision of Bloom's Taxonomy. New York: Longman.

Patria, A. J. M. (2019). 'Enhancing English language teaching and learning through Ipadagogy,' ACLL2019 Conference Proceedings.

Kihoza, P. Zlotnikova, I., Bada, J., and Kalegele, K. (2016). 'Classroom ICT integration in Tanzania: Opportunities and challenges from the perspectives of TPACK and SAMR models Patrick Kihoza Nelson Mandela African Institution of Science and Technology, Tanzania Irina Zlotnikova Botswana International University o,' International Journal of Education and Development using Information and Communication Technology (IJEDICT), 12(1) 